\title{
Coronavirus Disease 19 Pandemic and Extracorporeal Therapies in Intensive Care: "Bis Peccare in Bello Non Licet"
}

\author{
Omar Maoujoud Mohammed Asserraji Marouane Belarbi Nadir Zemraoui
}

Department of Nephrology, Avicennes Military Hospital, Faculty of Medicine, Cadi Ayyad University, Marrakech, Morocco

Dear Editor,

We enjoyed reading the article by Ronco et al. [1], the data presented, summarize actual knowledge regarding the benefit of extracorporeal organ support therapies in Novel coronavirus disease 19 (COVID-19) infected patients in the intensive care unit.

High frequency or renal abnormalities among COVID-19 patients is particularly interesting, as acute kidney injury (AKI) is a major risk factor for patients' mortality [2] . In this regard, the authors have raised the importance of continuous renal replacement therapies and new extracorporeal therapies such as hemoadsorption (HA) and hemoperfusion (HP) in the management of acute kidney injury in COVID-19 patients with cytokine storm syndrome, as such modalities are designed to remove the peaks of the circulating cytokines [3]. This approach is confirmed by recent published data from other Chinese teams [4-7], where these modalities have been used in 5-10\% of COVID-19 patients in ICU. Furthermore, in most severe cases, mortality has been linked also to cytokine storm syndrome [6, 7]. Admitting that HA and HP still require further investigations; these innovations should be considered now in the global extracorporeal organ support in COVID-19 patients. Also, it must be recognized that not all teams around the world are trained to use them, and in many countries these devices do not have marketing authorization. As in wartime, it is essential to secure all fronts, it is extremely urgent to start preparing the medical teams for the use of HA and
HP, especially in countries where the situation is still under control. International cooperation and sharing of reliable scientific information are needed, less affected countries should send health professionals to most affected ones, to help and to get experience in such modalities [8]. Furthermore, a fast track approval procedure must be launched in the markets where HP and HA are not authorized yet. Saving days in training and administrative procedures will save lives. As the ancients used to say: "Bis peccare in bello non licet," it is not permitted to err twice in war.

\section{Acknowledgment}

There are no acknowledgments to declare.

\section{Disclosure Statement}

The authors have no conflicts of interest to declare.

\section{Funding Sources}

There are no funding sources to declare.

\section{Author Contributions}

O.M. and M.A. contributed to the interpretation and writing of the manuscript. M.B. and N.Z. were responsible for the data collection, and all authors approved submission. 


\section{References}

1 Ronco C, Reis T, De Rosa S. Coronavirus Epidemic and Extracorporeal Therapies in Intensive Care: si vis pacem para bellum. Blood Purif. 2020, Epub ahead of print.

2 Kidney impairment is associated with in-hospital death of COVID-19 patients | medRxiv [Internet]. [cited 2020 Mar 10]. Available from: https://www.medrxiv.org/content/10.1 101/2020.02.18.20023242v1.

3 Ronco C, Navalesi P, Vincent JL. Coronavirus epidemic: preparing for extracorporeal organ support in intensive care. Lancet Respir Med. 2020 Mar;8(3):240-1.

4 Chen N, Zhou M, Dong X, Qu J, Gong F, Han $\mathrm{Y}$, et al. Epidemiological and clinical charac- teristics of 99 cases of 2019 novel coronavirus pneumonia in Wuhan, China: a descriptive study. Lancet. 2020 Feb;395(10223):507-13.

5 Shi Q, Zhao K, Yu J, Feng J, Zhao K, Zhang X, et al. Clinical characteristics of 101 non-surviving hospitalized patients with COVID-19: A single center, retrospective study [Internet]. Infectious Diseases (except HIV/AIDS); 2020 Mar [cited 2020 Mar 14]. Available from: http://medrxiv.org/lookup/doi/10.1101/2020 .03.04.20031039.

6 Zhang G, Hu C, Luo L, Fang F, Chen Y, Li J, et al. Clinical features and outcomes of 221 patients with COVID-19 in Wuhan, China [Internet]. Respiratory Medicine; 2020 Mar [cited 2020 Mar 14]. Available from: http:// medrxiv.org/lookup/doi/10.1101/2020.03.02. 20030452.

7 Ji C, Fan H, Zhang L, Huang B, Zhu M, Zhou $\mathrm{Y}$, et al. Retrospective Analysis of Clinical Features in 101 Death Cases with COVID-19 [Internet]. Intensive Care and Critical Care Medicine; 2020 Mar [cited 2020 Mar 14]. Available from: http://medrxiv.org/lookup/doi/10.110 1/2020.03.09.20033068.

8 Yuval noah H. In the Battle Against Coronavirus, Humanity Lacks Leadership. Time [Internet].2020 Mar 15 [cited 2020 Mar 28]; Available from: https://time.com/5803225/yuval-noahharari-coronavirus-humanity-leadership. 